\title{
Editorial: State-of-the-Art Research on C1q and the Classical Complement Pathway
}

\author{
Uday Kishore $^{1 *}$, Nicole M. Thielens ${ }^{2 *}$ and Christine Gaboriaud ${ }^{2}$ \\ ${ }^{1}$ College of Health and Life Sciences, Brunel University London, Uxbridge, UK, ${ }^{2}$ Institut de Biologie Structurale (IBS), \\ Université Grenoble Alpes, CEA, CNRS, Grenoble, France
}

Keywords: complement, $\mathrm{C} 1$ complex, $\mathrm{C} 1 \mathrm{q}, \mathrm{gC} 1 \mathrm{q}$ structure, $\mathrm{C} 1 \mathrm{~s}$, classical pathway activation, autoimmunity, emerging functions

The Editorial on the Research Topic

State-of-the-Art Research on C1q and the Classical Complement Pathway

Complement protein $\mathrm{C} 1 \mathrm{q}$ is a fascinating innate immune molecule. $\mathrm{C} 1 \mathrm{q}$ is the first subcomponent of the classical complement pathway. Its primary three-chain structure (A, B, and C chains), which is composed of a triple-helical collagen-like region and a C-terminal ligand-recognizing globular head (gC1q) domain, yields a tulip-like organization with six gC1q domains, each representing a het-

\section{OPEN ACCESS}

Edited and Reviewed by: Francesca Granucci, University of Milano-Bicocca, Italy

*Correspondence: Uday Kishore uday.kishore@brunel.ac.uk, ukishore@hotmail.com;

Nicole M. Thielens nicole.thielens@ibs.fr

Specialty section: This article was submitted to Molecular Innate Immunity, a section of the journal

Frontiers in Immunology

Received: 26 August 2016 Accepted: 20 September 2016 Published: 04 October 2016

Citation:

Kishore U, Thielens NM and Gaboriaud C (2016) Editorial: State-of-the-Art Research on

C1q and the Classical Complement Pathway.

Front. Immunol. 7:398. doi: 10.3389/fimmu.2016.00398 erotrimer (the C-terminal regions of the $\mathrm{A}, \mathrm{B}$, and $\mathrm{C}$ chains) (1). In addition to binding to immune complexes containing IgG and $\operatorname{IgM}$, the gC1q domain also engages with a number of self and non-self ligands. A summary of the structural basis of $\mathrm{Clq}$-ligand interactions has been elegantly presented in the review by Gaboriaud et al. For example, it shows that $\mathrm{C} 1 \mathrm{q}$ can recognize multiple ligands on the apoptotic cell surface, which illustrates its versatile surface recognition properties. A common binding area for several of these non-immune ligands has been observed in the subunit $\mathrm{C}$, which could play a role in restricting the activation of the classical complement pathway.

It has become evident over the course of the last two decades that the gC1q domain is widely conserved across a diverse range of vertebrate and invertebrate proteins (2). The functions of these proteins can range from being immunological to structural. Through a review article, Ghebrehiwet et al. have cited two examples of $\mathrm{Clq}$ functions that are distinct from its involvement in the classical pathway: its ability to induce apoptosis in prostate cancer cells, and to modulate vascularization for fetal-maternal interaction. Given the existence of a C1q-TNF superfamily based on the remarkable structural similarities between $\mathrm{C} 1 \mathrm{q}$ and TNF family members (1), a good argument has been made for a cytokine-like property of C1q. The complexity and diversity related to the functions of $\mathrm{C} 1 \mathrm{q}$ family have been greatly exemplified by a structure-function review article by Colombatti et al., who describe the functions associated with the gC1q domain of two C1q family members - such as EMILIN and multimerin. A slight structural variation from the prototypical structure, as revealed by the NMR solution structure, is insightful, purporting one residue in the interaction of gC1q domain with $\alpha_{4} \beta_{1}$ and $\alpha_{9} \beta_{1}$ integrins.

In recent years, a number of functions of $\mathrm{C} 1 \mathrm{q}$ have emerged that are complement independent. This is reflected in the local synthesis of $\mathrm{Clq}$ by various immune and non-immune cells. The diversity of $\mathrm{C} 1 \mathrm{q}$ functions includes its involvement in dendritic cell maturation, immune modulation, cell differentiation, cancer progression, neuronal synapse pruning, and pregnancy. This has been extensively summarized by Kouser et al. In the backdrop of a recent observation that C1q gene knockout mice show nearly all features of preeclampsia, the role of $\mathrm{Clq}$ in normal and complicated pregnancies 
has become a burning issue in the reproductive immunology. In this issue, Madhukaran et al. have reported a link between the expression of the transcription factor PU.1 and C1q in human trophoblasts and stromal cells, similar to DCs and macrophages, using early decidual tissue.

Given its involvement in a wide range of homeostatic functions, it is not surprising that $\mathrm{C} 1 \mathrm{q}$ is central to many human diseases. C1q, as a key molecule in self-tolerance mechanisms, is involved in clearing immune complexes and apoptotic/ necrotic cells. C1q-deficient mice have been shown to have lupus-like symptoms. However, this issue is further confounded by the fact that anti-C1q autoantibodies are found in a number of pathological situations, more so in systemic lupus erythematosus (SLE). These autoantibodies are certainly required for the development of lupus nephritis. Since $\mathrm{C} 1 \mathrm{q}$ itself is an IgG-binding protein, identification and characterization of anti-C1q autoantibodies is a challenging task. Mahler et al. have addressed the technicalities of this endeavor, while reassessing the pathological consequences of such autoantibodies in a disease context. In line with the involvement of $\mathrm{C1q}$ in tolerance and SLE, Ghebrehiwet et al. have addressed the importance of monocyte surface expressed $\mathrm{C} 1 \mathrm{q}$ in association with $\mathrm{C} 1 \mathrm{r}$ and $\mathrm{C} 1 \mathrm{~s}$. This review examines the role of cell-bound $\mathrm{C} 1 \mathrm{q}$ in capturing and processing circulating immune complexes and pathogen-associated molecular patterns (PAMPs). The ability of $\mathrm{C} 1 \mathrm{q}$ to modulate PAMP-recognizing receptors (PRRs) makes it a potent and versatile immune surveillance molecule of the innate immunity.

The final section of the issue is dedicated to the understanding of the mechanisms underlying activation of the classical pathway and their specific inhibition for therapeutic purposes.

In an original research article, Wijeyewickrema et al. aim at further deciphering the interaction of the $\mathrm{C} 1 \mathrm{~s}$ protease with its C4 protein substrate. Previous studies had provided evidence for homologous $\mathrm{C} 4$ interaction exosites in the CCP and serine protease domains of both C1s and MASP-2 (3). The authors focus here on the role of C1s Lys628 residue of the serine protease domain. Using site-directed mutagenesis and a peptide substrate library, they show that this residue plays a different role in cleaving peptide versus protein substrates by interacting with $\mathrm{C} 4$ in order to facilitate its cleavage. The architecture of the active site at this position is markedly different in C1s compared with MASP-2 (4), which might provide clues toward designing specific inhibitors of the classical pathway.

In a review article, Sharp et al. focus on complement inhibitors of the classical pathway for application in transfusion medicine. Uncontrolled antibody-initiated complement activation plays a central role in hemolytic diseases such as acute intravascular hemolytic transfusion reaction (AIHTR). The authors have

\section{REFERENCES}

1. Kishore U, Gaboriaud C, Waters P, Shrive AK, Greenhough TJ, Reid KBM, et al. C1q and tumor necrosis factor superfamily: modularity and versatility. Trends Immunol (2004) 10:551-61. doi:10.1016/j.it.2004.08.006 identified peptide inhibitors of C1 (PIC1) derived from a region of the coat protein of astrovirus with homology to human neutrophil peptide 1 that inhibits complement activation by binding to the collagen-like regions of $\mathrm{Clq}$ (5). They have developed a simple rat model of AIHTR for future preclinical studies of PIC1. A review of complement inhibitors, marketed as well as currently under development, is presented, and their therapeutic potential in transfusion and blood disorders is discussed.

In their perspective article, Gaboriaud et al. provide an update on the current knowledge about the structural basis of the mechanisms involved in the assembly and activation of the $\mathrm{C} 1$ complex. The main protein players involved in $\mathrm{C} 1$ activation and its control are presented together with the molecular dissection strategy used to define structure-function relationships of $\mathrm{C} 1$ subcomponents and to decipher key protein-protein interactions. However, the conformational changes required for allowing $\mathrm{C} 1$ activation following target binding are still not elucidated, and this is one among 16 still unanswered questions identified by the authors. Hopefully, new technological developments in structural biology, such as a combination of X-ray crystallography and electron microscopy, will help fulfilling this "mission impossible."

This special topic issues clearly highlights the diversity and complexity associated with structures and functions of C1q and C1q family members. We have come a long way in understanding the structural basis of the $\mathrm{gClq}$ interaction with self and non-self ligands. While additional members of C1q family are still being identified and characterized, the importance of the gC1q domain in the evolutionary history of animals is unique. From being a prototypical innate immune molecule, $\mathrm{C} 1 \mathrm{q}$ is now regarded as an independent modulator of a diverse range of functions that are not dependent on its involvement in the complement activation. These complement-independent functions of $\mathrm{Clq}$ are likely to be the major thrust of research in coming years.

\section{AUTHOR CONTRIBUTIONS}

All authors listed have made substantial, direct, and intellectual contribution to the work and approved it for publication.

\section{ACKNOWLEDGMENTS}

We are grateful to all the authors who contributed to this special issue of Frontiers in Immunology. We are also indebted to all the reviewers who took special care and attention in ensuring that all the accepted manuscripts reached the high standard we set for ourselves.

2. Ghai R, Waters P, Roumenina LT, Gadjeva M, Kojouharova MS, Reid KBM, et al. C1q and its growing family. Immunobiology (2007) 212:253-66. doi:10.1016/ j.imbio.2006.11.001

3. Duncan RC, Mohlin F, Taleski D, Coetzer TH, Huntington JA, Payne RJ, et al. Identification of a catalytic exosite for complement component $\mathrm{C} 4$ on the 
serine protease domain of C1s. J Immunol (2012) 189:2365-73. doi:10.4049/ jimmunol.1201085

4. Harmat V, Gál P, Kardos J, Szilágyi K, Ambrus G, Végh B, et al. The structure of MBL-associated serine protease- 2 reveals that identical substrate specificities of C1s and MASP-2 are realized through different sets of enzyme-substrate interactions. J Mol Biol (2004) 342:1533-46. doi:10.1016/j.jmb.2004.07.014

5. Hair PS, Gronemus JQ, Crawford KB, Salvi VP, Cunnion KM, Thielens NM, et al. Human astrovirus coat protein binds $\mathrm{Clq}$ and $\mathrm{MBL}$ and inhibits the classical and lectin pathways of complement activation. Mol Immunol (2010) 47:792-8. doi:10.1016/j.molimm.2009.10.006
Conflict of Interest Statement: The authors declare that the research was conducted in the absence of any commercial or financial relationships that could be construed as a potential conflict of interest.

Copyright (c) 2016 Kishore, Thielens and Gaboriaud. This is an open-access article distributed under the terms of the Creative Commons Attribution License (CC BY).

The use, distribution or reproduction in other forums is permitted, provided the original author(s) or licensor are credited and that the original publication in this journal is cited, in accordance with accepted academic practice. No use, distribution or reproduction is permitted which does not comply with these terms. 